Canadian

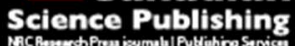

Canadian Journal of Microbiology Revue canadienne de de microbiologie

\title{
Ethanol-induced stress response of Staphylococcus aureus.
}

\begin{tabular}{|r|l|}
\hline Journal: & Canadian Journal of Microbiology \\
\hline Manuscript ID & cjm-2017-0221.R1 \\
\hline Manuscript Type: & Article \\
\hline Date Submitted by the Author: & O9-May-2017 \\
\hline Complete List of Authors: & $\begin{array}{l}\text { Pando, Jasmine M.; New Mexico State University, Biology } \\
\text { Pfeltz, Richard F.; BD Diagnostics } \\
\text { Cuaron, Jesus A.; New Mexico State University, Biology } \\
\text { Nagarajan, Vijayaraj; University of Southern Mississippi, Biological } \\
\text { Sciences } \\
\text { Mishra, Mukti N.; Oklahoma State University, Biochemistry and Molecular } \\
\text { Biology } \\
\text { Torres, Nathanial J.; Oklahoma State University, Biochemistry and } \\
\text { Molecular Biology } \\
\text { Elasri, Mohamed O.; University of Southern Mississippi, Biological Sciences } \\
\text { Wilkinson, Brian J.; Illinois State University, Biological Sciences } \\
\text { Gustafson, John E.; Oklahoma State University, Biochemistry and } \\
\text { Molecular Biology }\end{array}$ \\
\hline Keyword: & \begin{tabular}{l} 
Staphylococcus aureus, stress response, ethanol, stringent response \\
\hline
\end{tabular} \\
\hline
\end{tabular}




\section{Ethanol-induced stress response of Staphylococcus aureus.}

Jasmine M. Pando ${ }^{1}$, Richard F. Pfeltz ${ }^{2}$, Jesus A. Cuaron ${ }^{1}$, Vijayaraj Nagarajan ${ }^{4}$, Mukti N. Mishra ${ }^{5}$, Nathanial J. Torres ${ }^{5}$, Mohamed O. Elasri ${ }^{4}$, Brian J. Wilkinson ${ }^{3}$, and John E. Gustafson ${ }^{1,5^{*}}$

${ }^{1}$ Department of Biology, New Mexico State University, Las Cruces, NM.

${ }^{2}$ BD Diagnostic Systems, Microbiology R\&D Department, Sparks, MD.

${ }^{3}$ Microbiology Group, School of Biological Sciences, Illinois State University, Normal, IL,

${ }^{4}$ Department of Biological Sciences, University of Southern Mississippi, Hattiesburg, MS.

${ }^{5}$ Department of Biochemistry and Molecular Biology, Oklahoma State University, Stillwater, OK.

${ }^{*}$ Corresponding author. Mailing address: Department of Biochemistry and Molecular Biology, Oklahoma State University. Phone: (405)-744-6189. Fax: (405)-744-7799. Email: john.gustafson@okstate.edu. 


\section{0_File000028_238686856.doc}

\section{Abstract}

Transcriptional profiles of two unrelated clinical methicillin-resistant S. aureus (MRSA) isolates were analyzed following $10 \% \mathrm{v} / \mathrm{v}$ ethanol challenge (15 min), which arrested growth but did not reduce viability. Ethanol-induced stress (EIS) resulted in differential gene expression of 1091 genes, 600 common to both strains, of which 291 were upregulated. With the exception of the down-regulation of genes involved with osmotic stress functions, EIS resulted in the up-regulation of genes that contribute to stress response networks, notably those altered by oxidative stress, protein quality control in general, and heat shock in particular. In addition, genes involved with transcription, translation and nucleotide biosynthesis were down-regulated. reIP, which encodes a small alarmone synthetase (ReIP), was highly up-regulated in both MRSA strains following ethanol challenge and relP inactivation experiments indicated that this gene contributed to EIS growth arrest. A number of persistence-associated genes were also up-regulated during EIS, including those that encode toxin-antitoxin systems. Overall, transcriptional profiling indicated that the MRSA investigated responded to EIS by entering a state of dormancy and altering the expression of elements from cross protective stress response systems in an effort to protect preexisting proteins.

Key words: Staphylococcus aureus; ethanol; stress response; stringent response; growth inhibition. 


\section{0_File000028_238686856.doc}

\section{Introduction}

Staphylococcus aureus expresses an extensive suite of virulence factors, causes a broad range of significant diseases, and is a leading cause of healthcare-associated infections (HAI) (Morell and Balkin, 2010; Tang and Stratton, 2010). Methicillin-resistant S. aureus (MRSA) is of particular concern due to its propensity to become resistant to multiple antibiotics (Morell and Balkin, 2010; Tang and Stratton, 2010). Although viable MRSA can be recovered from disinfected hospital room surfaces, it is the carriage of MRSA amongst patients and on the hands of health care providers that has been a primary focus of HAl control efforts for several decades (Huang et al. 2006; McLaws 2015; Siegel et al. 2007). Hand hygiene is considered the single most effective approach to controlling the spread of infectious agents including MRSA within healthcare environments. Hand hygiene encompasses both hand-washing with plain or antiseptic soap, as well as the use of alcohol-based hand rubs (ABHR). ABHR use reduces both MRSA transmission within health care facilities and MRSA HAI, and $\mathrm{ABHR}$ are routinely employed as a convenient alternative to hand washing in the community (Gordin et al. 2005; Siegel et al. 2007; Todd et al. 2010; World Health Organization 2009). ABHR also conveniently evaporate soon after application without requiring towels for drying hands. However, the volatility of alcohols can also allow for the subsequent re-growth of surviving microorganisms on the skin following recovery from alcohol-induced sub-lethal injury (Lilly et al. 1979). The bactericidal activity of alcohols is attributed to a rapid denaturation of protein and membrane structures, which subsequently leads to the loss of the membrane barrier, loss of the proton motive force 


\section{0_File000028_238686856.doc}

and transport functions, and the inhibition of protein synthesis and cell division (Chatterjee et al. 2006; McDonnell and Russell 1999).

A number of studies have investigated the effects of low ethanol concentrations on $S$. aureus. Although $0.1 \%(\mathrm{v} / \mathrm{v})$ ethanol does not affect $S$. aureus growth rate, it does significantly delay post-stationary phase recovery and return to active growth, as well as the transition from primary to secondary metabolite catabolism, even after the ethanol had been completely depleted from the growth medium (Chatterjee et al. 2006). Ethanol at concentrations as low as $0.03 \% \mathrm{v} / \mathrm{v}$ can also induce the expression of $S$. aureus heat shock proteins (Qoronfleh et al. 1998). Korem et al. (2010) reported gene expression changes in S. aureus following $24 \mathrm{hr}$ growth in agar medium with $3 \% \mathrm{v} / \mathrm{v}$ ethanol that included the up-regulation of oxidative stress responses, secreted and surface virulence factors, and biofilm production capability.

Growth cessation is the common feature of survival strategies employed by microorganisms to remain viable during nutrient starvation and other inhospitable environmental conditions. These strategies, grouped under the term dormancy, are associated with non-replicative, reversible physiologic states that arise without need for genetic alterations, have interrelated mechanisms, and include persistence, biofilms, viable but non-culturable (VBNC) cells, antimicrobial and/or stress tolerance, and the stringent response (Ayrapetyan et al. 2015; Wood et al. 2013).

The stringent response is initiated by the synthesis of nucleotide guanosine penta and tetraphosphates ((p)ppGpp), referred to as alarmones, in response to limited nutrient availability, particularly amino acids. Alarmone accumulation results in a dramatic down-regulation of genes involved with protein and nucleotide biosynthesis 


\section{0_File000028_238686856.doc}

and many transport functions, while up-regulating amino acid biosynthesis and uptake systems genes, as well as select virulence determinants (Dalebroux et al., 2010). In most bacteria, the alarmone concentration is primarily determined by the activities of RelA, a bifunctional (p)ppGpp synthetase/hydrolase. Firmicutes also possess genes for two small alarmone synthetases (SAS), designated RelP and RelQ in S. aureus, which have weaker synthetase activities and lack the $\mathrm{N}$-terminal hydrolase and C-terminal ribosome-interacting sensory domains. S. aureus SASs are induced by alkaline or oxidative stress conditions, and by cell wall-active antimicrobials such as vancomycin or ampicillin (Gaca et al. 2015; Kriel et al. 2012).

The stringent response is also involved with a wide range of stress responses and dormancy or persister states (Cohen et al. 2013; Gaca et al. 2015). Other stress systems besides the stringent response that support persistence include the SOS-, heat-, and oxidative stress- response, as well as toxin-antitoxin (TA) modules (reviewed by Zhang 2014). A common objective of all of these stress response mechanisms is the protection and repair of key cellular components such as proteins and nucleic acids (Cohen et al. 2013; Gaca et al. 2015; Zhang et al., 2014).

Earlier studies with S. aureus and ethanol exposure focused on the organism's adaptation to and subsequent growth in the presence of sub-inhibitory ethanol levels. The purpose of this study was to understand the basis of the survival of this important pathogen during an ethanol treatment capable of inducing bacteriostasis, information whose absence is surprising given the importance of ABHR to HAI control. 
12509900_File000028_238686856.doc

\section{Materials and Methods}

\section{S. aureus strains and ethanol susceptibility and viability assays}

Unless otherwise noted all chemicals were purchased from Sigma-Aldrich Co. (St Louis, MO) and growth media were purchased from Becton, Dickinson and Company (Sparks, MD). Ethanol used for minimum inhibitory concentration (MIC) and minimum bactericidal concentration (MBC) determinations (AAPER Alcohol and Chemical Co., Shelbyville, KY) was first filter-sterilized with a $0.22 \mu \mathrm{m}$ nylon membrane.

MICs and MBCs to ethanol were determined with $1 \% \mathrm{v} / \mathrm{v}$ increments in tightlycapped tubes as described by Davis et al. (2005) for a panel of 106 well-characterized clinical MRSA (O'Brien et al. 2005, Delgado et al. 2007). Two unrelated strains representing different Smal-PFGE profiles, LP9 and MM66 (Delgado et al. 2007, Matyi et al. 2014), were selected from this panel and utilized for the ethanol challenge studies and transcriptional profiling experiments.

To determine the effects of ethanol on LP9 and MM66 viability, $1 \% \mathrm{v} / \mathrm{v}$ inocula from overnight $\mathrm{MHB}$ cultures were added to fresh $\mathrm{MHB}$ and grown to an $\mathrm{OD}_{625}$ of 0.5 at $37^{\circ} \mathrm{C}$ with shaking at $200 \mathrm{rpm}$. Ethanol was then added to a final concentration of $10 \%$ $\mathrm{v} / \mathrm{v}$ and at subsequent time points the $\mathrm{OD}_{625}$ was recorded, each culture was diluted in fresh MHB, and aliquots of each dilution were plated onto MHA. CFU/mL values for each dilution were calculated based on colony counts following overnight growth at $37^{\circ} \mathrm{C}$. 
12509900_File000028_238686856.doc

\section{Microarray and qRT-PCR analysis}

S. aureus DNA microarrays (version 6) were used for transcriptional profiling of LP9 and MM66 (MHB cultures $\left.\mathrm{OD}_{580}=0.5,37^{\circ} \mathrm{C}\right)$ following $10 \%$ ethanol challenge for 15 min using protocols provided by the Pathogen Functional Genomics Resource Center (PFGRC) (http//:pfgrc.tigr.org) as described in Muthaiyan et al. 2008. Duplicate microarrays for LP9 and MM66 were hybridized and analyzed, and ORFs altered 2.0fold and above were determined to be significant $(P<0.05)$. The data discussed in this publication have been deposited in NCBI's Gene Expression Omnibus (Edgar et al. 2002) and are accessible through GEO series accession number GSE17391 (http://www.ncbi.nlm.nih.gov/geo/query/acc.cgi?acc=GSE17391). An ethanol challenge time of 15 min was selected to ensure uniform $S$. aureus populations prior to transcriptional profiling and minimize intra-experiment variation.

ORF IDs were mapped to the N315 genome when possible, otherwise they were from the six $S$. aureus genomes on the microarray. Gene functional categories were tailored to facilitate the analysis of this study's results, including segregation of stressresponsive genes into a distinct category, identifying growth arrest-specific genes, placing transcriptional regulators in function-specific categories, and dividing several functional categories into sub-categories.

Primers listed in Table 1 were employed to validate by quantitative real-time PCR (qRT-PCR), as previously described (Riordan et al. 2007), selected genes from the 


\section{0_File000028_238686856.doc}

microarray studies whose expression was altered in response to $10 \% \mathrm{v} / \mathrm{v}$ ethanol (Table 2).

Staphylococcus aureus Transcriptome Meta-Database (SATMD) (Nagarajan and Elasri 2007) was used to compare the LP9 and MM66 ethanol gene expression profiles to 250 S. aureus transcriptional profile datasets publicly available when SATMD was accessed, of which 158 profiles were from environmental factor studies and 92 from regulatory gene mutants.

\section{Construction and characterization of reIP mutants}

reIP deletion mutants of strain JE2 were produced utilizing pKOR technology (Bae and Schneewind 2006). Briefly, upstream (1006 bp) and downstream (991 bp) flanking regions of reIP were amplified using the attB1-relP-up:F and relP-up:R:Sacll, and reIP-down:F:Sacll and attB1-relP-down:R primer sets, respectively (Table 1). The amplicons produced were then digested with Sacll, ligated together and cloned into pKOR1 utilizing the BP clonase system (Invitrogen) to produce plasmid pKOR1- $\Delta$ reIP. S. aureus strain JE2 was electroporated with pKOR1- $\Delta r e I P$, and the reIP gene was then deleted following the protocol previously described (Bae and Schneewind 2006) producing strain JE2 $\triangle$ relP. The deletion of relP was confirmed by amplification of the genomic DNA of JE2 and JE2 $\triangle$ reIP utilizing reIP specific primers (Table 1). JE2 genomic DNA produced an amplicon of $700 \mathrm{bp}$, while JE2 $\Delta$ relP DNA did not produce any amplicon, confirming reIP deletion in this mutant. To complement this mutant the relP gene was first amplified with its native promoter using the primers reIP:F:Kpnl and 


\section{0_File000028_238686856.doc}

reIP:R:Xbal (Table 1) and cloned into Kpnl/Xbal digested pLI50 (Lee et al. 1991) to produce pLI50::reIP. This plasmid was then electroporated in JE2 $\Delta$ relP to produce strain JE2 $\Delta$ reIP-pLI50::reIP. Strains JE2, JE2 $\Delta$ reIP, JE2 $\Delta$ reIP-pLI50::reIP and appropriate pLI50 controls were characterized in an ethanol growth inhibition assay in triplicate. Briefly, overnight MHB cultures $\left(37^{\circ} \mathrm{C}\right.$ with shaking at $\left.200 \mathrm{rpm}\right)$ were used to inoculate $20 \mathrm{~mL}$ of fresh $\mathrm{MHB}$ to an $\mathrm{OD}_{580 \mathrm{~nm}}$ of 0.05 . After subsequent growth to an $\mathrm{OD}_{580 \mathrm{~nm}}$ of $\sim 0.30$, the $20 \mathrm{~mL}$ cultures were equally divided between two $50 \mathrm{~mL}$ flasks, of which one culture was challenged with the addition of $9 \%$ v/v ethanol. Growth was then monitored by measuring $\mathrm{OD}_{580 \mathrm{~nm}}$ at various time intervals.

\section{Results and Discussion}

\section{MRSA susceptibility to ethanol}

Ethanol MICs of the 106 clinical MRSA ranged from $6 \%$ to $11 \% \mathrm{v} / \mathrm{v}$ and the MBCs ranged from $8 \%$ to $15 \%$, with $9 \%$ and $13 \%$ as the most common MIC and MBC values, respectively (Fig. 1, Table S $1^{1}$ ). Since $94 \%$ of the MRSA demonstrated an MIC below $10 \%$ v/v ethanol and $92 \%$ of the MRSA had an MBC above this concentration, $10 \% \mathrm{v} / \mathrm{v}$ ethanol was chosen as the test condition to study the ethanolinduced stress (EIS) response. Based on their high and low ethanol susceptibilities, strains LP9 and MM66 were selected for microarray analysis. MRSA MM66 was more ethanol-sensitive than most of the MRSA tested, with an MIC of $7 \%$ and MBC of $10 \%$ v/v ethanol. MRSA LP9, conversely, was more ethanol-tolerant than most of the 106 clinical MRSA, with an MIC of $9 \%$ and MBC of $15 \% \mathrm{v} / \mathrm{v}$ ethanol. 


\section{0_File000028_238686856.doc}

The addition of $10 \% \mathrm{v} / \mathrm{v}$ ethanol to MM66 and LP9 cultures halted the growth of both strains (Fig. $S 1^{1}$ ), however the number of cells from both strains surviving at 15 min post-ethanol addition $\left(4.3 \times 10^{7} \mathrm{CFU} / \mathrm{mL}\right.$ for MM66 and $4.1 \times 10^{7} \mathrm{CFU} / \mathrm{mL}$ for LP9) was not appreciably reduced compared to time $0\left(6.0 \times 10^{7} \mathrm{CFU} / \mathrm{mL}\right.$ for MM66 and 4.8 $\times 10^{7} \mathrm{CFU} / \mathrm{mL}$ for LP9). In fact, both strains survived quite well up to three $\mathrm{hr}$ in $10 \% \mathrm{v} / \mathrm{v}$ ethanol $\left(3.5 \times 10^{7} \mathrm{CFU} / \mathrm{mL}\right.$ for MM66 and $6.6 \times 10^{7} \mathrm{CFU} / \mathrm{mL}$ for LP9) (Fig. S1 $\left.{ }^{1}\right)$. These results demonstrated that RNA isolated from cultures after a 15 min exposure to $10 \%$ v/v ethanol for microarray and qRT-PCR studies were from cells that were viable, but not dividing. We define the transcriptional response we are describing as the $S$. aureus ethanol-induced stress (EIS) response.

\section{The S. aureus EIS transcriptional profile}

The differences in the EIS transcriptional response of MM66 and LP9 are attributed to the strains unique genetic background (Delgado et al. 2007) and different ethanol susceptibilities (this study). MM66 also has a graS mutation which affects the activity of the two component GraRS system and supports the hetero-vancomycinintermediate phenotype expressed by this strain (Matyi et al. 2014).

Gene expression changes induced during EIS are listed in Table S2 ${ }^{1}$. A total of 1691 expression changes occurred between strains LP9 and MM66, involving a total of 1091 genes (Table S3 ${ }^{1}$ ). Three up-regulated genes altered by $10 \%$ ethanol were confirmed by qRT-PCR in both MM66 and LP9 (Table 2). Six hundred of the 1091 genes were differentially regulated in both strains (Fig. 2A), of which 291 were up- 


\section{0_File000028_238686856.doc}

regulated (Fig. 2B) and 307 were down-regulated (Fig. 2C) in both strains. All but two (SA0012 and SA0922) of the 600 genes common to both strain data sets were differentially regulated in the same direction in both strains (Tables S2 ${ }^{1}$ ).

All expression changes in both strains challenged with ethanol are presented graphically by gene functional category in Figure 3 . The overall ratio of increased to decreased gene expressions of all 1091 altered genes was 1:1.1 (Table S3 $\left.{ }^{1}\right)$, and genes in the central metabolism and growth arrest and virulence functional categories were evenly distributed between up- and down-regulation (Fig. 3, Table S3 ${ }^{1}$ ). Overall, genes in the DNA replication, recombination and repair, hypothetical proteins/unknown function, and stress response functional categories were predominantly up-regulated (Fig. 3, Table S3 ${ }^{1}$ ). In contrast, genes in the amino acid and protein metabolism, cell envelope metabolism and resistances, nucleotide metabolism, transcription, cofactors and secondary metabolites and especially transport functional categories were predominantly down-regulated (Fig. 3 , Table S3 ${ }^{1}$ ). Ethanol challenge induced an expression change of $\geq 15$-fold in 33 genes in LP9 and/or MM66 (Table 3). One of these genes (SA2308) was only up-regulated in LP9 and another (cwrA) was only upregulated in MM66 (Table 3).

During EIS, there was almost a 2:1 ratio favoring up-regulation for genes in the hypothetical protein and unknown function categories (Fig. 3), also reported by Anderson et al. (2006) for heat shock. These categories accounted for $34.2 \%$ of the total EIS transcriptional profile (Table S3 ${ }^{1}$ ), typical of the $30-40 \%$ expected from genomic and transcriptomic studies (Prosser et al. 2014). 


\section{0_File000028_238686856.doc}

The 97 genes assigned to the ad hoc stress response functional category were segregated into six sub-categories (Fig. 4, Table S3 ${ }^{1}$ ). Differential gene expression was equally divided between up- and down-regulation for the 14 cold shock sub-category genes (Fig. 4, Table S3 ${ }^{1}$ ). In contrast, genes involved with stress responses to heat shock, oxidative shock, and those assigned to the general stress response and other stress response sub-categories were predominantly up-regulated (Fig. 4, Table S3 ${ }^{1}$ ). Included in the general stress response sub-category were genes encoding protein quality control functions and global transcriptional regulators with broad functions well beyond heat shock, such as those of the $c / p C$ operon (Graham et al. 2013), as well as genes induced by multiple stresses that encode proteins of unknown function such as asp23 (Campbell et al. 2012; Senn et al., 2005; Shrihari and Singh 2012).

Heat shock activates protein quality control functions that protect protein integrity and functionality by means of protein chaperones which mediate proper folding of nascent proteins and assist proteases that degrade accumulated or improperly folded proteins (Anderson et al. 2006, Graham et al. 2013). The heat shock sub-category contained nine genes, all up-regulated in ethanol challenged LP9 and MM66 (Fig. 4), for an up-regulation to down-regulation ratio of 18:0, the most lopsided of any gene categorization examined.

Oxidative stress response mechanisms are often credited as an underlying mechanism leading to antimicrobial tolerance during growth-arrested conditions such as stringency and persistence (Geiger et al. 2014; Zhang 2014). Genes of the oxidative stress category (Fig. 4, Table S3 ${ }^{1}$ ) are predominantly up-regulated during the EIS response. Oxidative stress response and DNA replication, recombination and repair 


\section{0_File000028_238686856.doc}

genes had a 1.8 - 2:1 ratio of up- to down-regulation during EIS (Fig. 3 and 4, Table $S 3^{1}$,). These two responses are interrelated, as strong oxidative stress can trigger the SOS response (Chang et al. 2006, Gaupp et al. 2012). The SOS response protects against the effects of DNA damage via DNA recombination and repair systems. In contrast with these overall increases in the expression of stress response genes, the genes involved with osmotic stress displayed a ratio of 8:1 in favor of down-regulation (Fig. 4).

As evidence of a general stress response activation by ethanol challenge, some of the highest up-regulated genes include eight characterized genes involved with stress responses, listed in Table 3, including genes involved directly with the heat shock (grpE, groES) (Campbell et al. 2012) and stringent responses (reIP) (Geiger et al. 2014). The remaining five include $c / p B$, which encodes a molecular chaperone (Graham et al. 2013); and the entire $c / p C$ operon which consists of $c t s R$ (encodes a negative regulator of the $c l p C$ operon and other stress response genes), mcs $A$ (encodes a redox sensitive activator of the CtsR activity modulator McsB) and mcsB (encodes a protein required for various stress responses), which are involved with the regulation of the clpC operon. $c / p C$, which encodes the ATPase subunit of the ClpC protease required for stress resistance (Elsholz et al. 2011; Wozniak et al. 2012) (Table 3), and four genes involved with protein fate were also up-regulated in both strains when challenged with ethanol (Table 3).

While genes in the amino acid metabolism and the protein fate sub-categories were generally up-regulated (Fig. 4), the 88 genes encoding protein synthesis functions were differentially regulated by a ratio of $8: 1$ in favor of down-regulation (Fig. 4, Table 


\section{0_File000028_238686856.doc}

$\left.S 3^{1}\right)$. Forty-nine genes encoding ribosomal proteins for instance yielded a total of 89 expression changes, 86 of which were down-regulations and only 3 were up-regulations $\left(\right.$ Table S $\left.4^{1}\right)$. Consistent with the dramatic down-regulation of protein synthesis machinery, the $r p o A$ (Table 3), rpoB, rpoC, and rpoE genes that encode components of the core RNA polymerase, and the $r p o D$ gene encoding the primary sigma factor SigA that directs transcription initiation in actively growing cells (Morikawa et al. 2012), were all down-regulated during EIS (Table S2 ${ }^{1}$ ). Collectively, this demonstrates that under EIS conditions, synthesis of mRNA and protein are down-regulated and factors involved with maintaining existing protein functions are up-regulated.

Genes assigned to the stringent response sub-categories were generally downregulated (Fig. 4), and genes encoding all three S. aureus alarmone synthetases were differentially regulated in one or both of the strains investigated following ethanol challenge. The bifunctional GTP synthetase/hydrolase-encoding relA was downregulated three-fold in LP9 (Table S2 ${ }^{1}$ ), the SAS-encoding re/Q was up-regulated twofold in MM66 (Table S2 ${ }^{1}$ ), and the gene encoding the SAS RelP was highly upregulated in both LP9 and MM66 (Table 3).

A considerable amount of evidence links both RelP and RelQ to cell envelope stress responses (Geiger et al. 2014). Both are highly up-regulated in response to cell wall-active antimicrobials and the deletion of reIP and re/Q leads to diminished survival rates when S. aureus is challenged with these drugs (Gaca et al. 2015). The magnitude of relP induction in this study prompted an examination of the effect of relP inactivation on S. aureus survival after an ethanol challenge. In unchallenged MHB cultures, JE2, JE2 $\Delta$ reIP, JE2 $\Delta r e I P-p L I 50:: r e I P$ and the appropriate pLI50 control strains all grew at an 


\section{0_File000028_238686856.doc}

identical rate for up to $12 \mathrm{hr}$ (data not shown). Eight hr after the addition of $9 \% \mathrm{v} / \mathrm{v}$ ethanol, the JE2 $\Delta$ reIP and JE2 $\Delta r e I P$-pLI50 cultures grew faster than those of the other strains (Fig. 5). Upon complementation of the relP deletion in trans, JE2 $\Delta$ relPpLI50::relP then grew more slowly than either JE2 or JE2-pLI50 (Fig. 5). A reduced growth rate was observed for JE2AreIP-pLI50::relP compared to the parent strain that is likely associated with a plasmid copy number effect. These results suggest that RelP plays a role in curtailing the active growth state when cells are challenged with ethanol under the conditions of this study.

Of the ten genes assigned to the persistence sub-category (Fig. 4), only the menaquinone pathway gene menA that has been linked to persistence in Mycobacterium tuberculosis (Zhang et al. 2012) was down-regulated in MM66 (Table S2 ${ }^{1}$ ). Up-regulated in both LP9 and MM66 were persistence-associated genes encoding an inorganic phosphate transporter component ( $p s t B)$, trans-translation element $30 \mathrm{~S}$ ribosomal protein $\mathrm{S} 1$ (rpsA), and a homolog of a GntR family transcriptional regulator up-regulated during M. tuberculosis persistence (SA1748) (Donegan et al. 2014; Overton et al. 2011; Zhang et al. 2012) (Table S2 ${ }^{1}$ ). Five of the genes assigned to the persistence sub-category encode components of three $S$. aureus TA modules. yoeBsa1 and yefM-sa1 which encode the YefM-YoeB-sa1 TA module were both upregulated in LP9 and MM66, yoeB-sa2 and yefM-sa2 which encode the YefM-YoeB-sa2 TA module were up-regulated in MM66, and mazF which encodes the MazEF TAmodule toxin was also up-regulated only in MM66 (Larson and Hergenrother 2014; Schuster et al. 2015) (Table S2 ${ }^{1}$ ). TA modules are up-regulated in response to treatment with protein synthesis inhibitors (Reiss et al. 2012; Donegan et al. 2010) or 


\section{0_File000028_238686856.doc}

heat shock (Anderson et al. 2006), and Schuster et al. (2015) reported that mazEF participates in tolerance to cell wall active antibiotics.

The 43 genes assigned to the virulence functional category had an up- to downregulation ratio of 1:1 (Fig. 3 , Table $S 2^{1}$ ). Some two-thirds of the genes with reduced expression in the virulence factor cell surface sub-category (Fig. 4, Table S2 ${ }^{1}$ ) were attributable to genes encoding capsule biosynthesis functions for strain MM66. Furthermore, a number of genes encoding virulence factor gene regulators (Bronner et al. 2004; Chueng et al., 2004; Flannagan and Clewell, 2002; Meier et al., 2007) were down-regulated in either LP9 (sarS, spoVG, and arIR) or MM66 (saeR, camS, agrA, $i c a R$ and $\operatorname{agr} D$ ) or both strains ( $\operatorname{agr} C)$ following ethanol challenge (Table S2 ${ }^{1}$ ), indicative of cell surface alterations during EIS.

Discounting capsule biosynthetic genes down-regulated in MM66, genes encoding secreted virulence factors were predominantly up-regulated by EIS. It has been widely reported that environmental stress responses such as the stringent response (Reiss et al. 2012), heat shock (Anderson et al. 2006), cell wall active antimicrobials (Song et al. 2012), and sub-inhibitory ethanol concentration (Korem et al. 2010) also up-regulate virulence. Anderson et al. (2006) postulated that the upregulation of extracellular virulence determinants in response to stress allows distressed cells to lay the groundwork to resume growth by degrading host tissues so nutrients would be available when environmental conditions were once again hospitable. This explanation is consistent with the up-regulation of secreted virulence factors by LP9 and MM66 challenged with ethanol at a time of compromised membrane function and minimal metabolic activity. 


\section{0_File000028_238686856.doc}

\section{Comparison of the EIS transcriptional profile to other S. aureus stress response profiles}

SATMD transcriptional profiles were interrogated with respect to the 291 upregulated genes common to both strains during EIS in an effort to identify transcriptional responses similar to that of EIS. Four growth-arrested transcriptional profiles had at least $40 \%$ of their up-regulated genes in common with the $291 \mathrm{EIS}$ up-regulated genes. The top up-regulated high-overlap comparator transcriptional profiles were: heat shock at $43^{\circ} \mathrm{C}$ for 10 min (25 genes in common, Fleury et al., 2009); the lipoglycopeptide enduracidin at 10 X MIC for 60 min (96 genes in common, Song et al., 2012); vancomycin at 10 X MIC for 60 min by (69 genes in common, Song et al. 2012); and 5 min pH 4.5 acid shock (69 genes in common, Bore et al., 2007).

Table $S 5^{1}$ is constructed from a list of 85 up-regulated genes present in three or four of the high-overlap transcriptional profiles and the EIS profile. No single gene was up-regulated in all five profiles, and stress response, hypothetical proteins/unknown function, and central metabolism and growth arrest were the predominant functional categories in terms of common up-regulated genes (Fig. 6). These three categories and cell envelope metabolism and resistances were the only functional categories that included genes from all five profiles (Fig. 6). Protein quality control genes assigned to general and heat shock stress response sub-categories, along with oxidative stress response genes, comprised the majority of the stress response functional category members (Table S5 ${ }^{1}$ ). Eleven of the 33 EIS high expression-change genes (Table 3 ) were also up-regulated in two or three of the four high-overlap comparator profiles 


\section{0_File000028_238686856.doc}

(Table 4). Present among these 11 genes (Table 4) were relP, and seven stress response genes from the CtsR regulon including the entire $c / p C$ operon (Michel et al. 2006). These genes also included those encoding a hypothetical translocase subunit (SA1215), a virulence factor, and a hypothetical xenobiotic response element (XRE) transcriptional regulator. XRE family regulators are involved with mobilizing genetic elements, (Ibarra et al. 2013) and have also been associated with alarmone control, growth arrest and oxidative stress in Rhizobium etli (Vercruysse et al. 2011). SA1215 encodes a hypothetical protein predicted to be a homolog of the SecD/SecF preprotein subunit of the staphylococcal general Sec preprotein translocase complex, and the adjacent gene SA1216 encodes a second putative protein fate effector, oligoendopeptidase F. Recently it was reported that increased expression of yajC, which encodes a different subunit of the staphylococcal general Sec translocase complex, is associated with $10 \%$ ethanol tolerance in Lactobacillus buchneri (Liu et al. 2016). Collectively, the 11 genes in Table 4 encoded protein quality control and growth arrest functions, and one virulence factor.

\section{Conclusions}

E. coli adapts to growth in liquid culture containing $5 \% \mathrm{v} / \mathrm{v}$ ethanol by reducing the lipid-to-protein ratio and modifying the fatty acid composition of the plasma membrane to increase membrane rigidity (Barker and Park 2001, Chiou et al. 2004, Dombek and Ingram 1984). Previously Fried and Novick (1973) reported that growth arrest of $E$. coli by carbon starvation imparted protection from the lethal effects of a 


\section{0_File000028_238686856.doc}

subsequent $9.3 \% \mathrm{v} / \mathrm{v}$ ethanol challenge. Chatterjee et al. (2006) reported that $S$. aureus completely metabolized very low levels of ethanol $(\leq 0.1 \% \mathrm{v} / \mathrm{v})$ in liquid culture over 24 hr. Korem et al. (2010) evaluated the transcriptional profile of S. aureus 8325-4 after 24 hr growth with $3 \% \mathrm{v} / \mathrm{v}$ ethanol and reported a relatively modest 95 up-regulated and 18 down-regulated genes. No protein quality control, heat shock-specific, or alarmone synthesis genes were induced, and overall results suggested a relatively mild stress condition to which $S$. aureus readily adapted to by means of membrane lipid modification, ethanol catabolism, and generally minor metabolic adjustments.

In stark contrast to the $3 \%$ ethanol adaptation transcriptional profile (Korem et al. 2010), the EIS profile did not indicate any attempt to metabolize ethanol or counter altered membrane fluidity. Instead there was a dramatic down-regulation of genes in the amino acid and protein synthesis, cell envelope metabolism and resistances, cofactors and secondary metabolites, nucleotide metabolism, and transport functional categories that indicated general metabolic shutdown in response to an overwhelming ethanol assault. The EIS transcriptional profile analysis also revealed that genes in the DNA replication, recombination and repair and stress response functional categories were predominantly up-regulated. Furthermore, the overall growth arrested profile exhibited by LP9 and MM66 during EIS relied on the selective deployment of stress responses and metabolic regulatory elements (SAS ReIP and TA modules) associated with the persister phenotype. Under EIS conditions where new protein synthesis was inhibited and the integrity of existing proteins faced a specific and serious threat, $S$. aureus concentrated its efforts on protecting existing catalytic potential, presumably to retain the capability for later resumption of growth. At the same time, defense of the 


\section{0_File000028_238686856.doc}

membrane barrier and osmoregulatory functions were abandoned in the face of the ethanol assault.

The unique aspect of this study was the use of ethanol at a concentration high enough to halt $S$. aureus growth. This was far below the $70-85 \%$ recommended for ABHR products to be effective, but ABHR exposure times are only 15-30 seconds while for EIS the exposure time was greatly extended to 15 min. S. aureus exhibited an impressive display of resilience and metabolic resourcefulness, resulting in an ethanol tolerance just below that of lactic acid bacteria used in the fermentation industry (Lee et al. 2012). The practical consequence of this study is reinforcement of the importance of full compliance by health care workers with ABHR recommendations with respect to ethanol content, application volume, treatment time, thoroughness of hand coverage, and ensuring hands are otherwise clean and dry before application, if ABHR are expected to be effective against MRSA.

\section{Acknowledgements}

All authors wish to acknowledge support from the National Institutes of Health: SC1GM083882-01 (JEG); R25 GM07667-30 (NMSU-MARC PROGRAM); S06 GM61222-05 (JC, NMSU-MBRS-RISE PROGRAM); and P20GM103451 (NM-INBRE program). JP also acknowledges the support of the NSF-NMSU-AMP (HRD0331446) program. The Oklahoma Agricultural Experimental Station also supplied funding to complete this research. All authors would also like to acknowledge the experimental contributions of Song Yang, Atul K. Singh, John Rivera and Joanne M. Dupre, and critical insight from Shelly L. Lusetti. 
12509900_File000028_238686856.doc

\section{References}

Anderson, K. L., Roberts, C., Disz, T., Vonstein, V., Hwang, K., Overbeek, R., Olson, P. D., Projan, S. J., and Dunman, P. M. 2006. Characterization of the Staphylococcus aureus heat shock, cold shock, stringent, and SOS responses and their effects on logphase mRNA turnover. J. Bacteriol. 188(19): 6739-6756.

Ayrapetyan M., Williams T. C., and Oliver J. D. 2015. Bridging the gap between viable but non-culturable and antibiotic persistent bacteria. Trends Microbiol. 23:7-13. doi: 10.1016/j.tim.2014.09.00

Bae, T. and Schneewind, O. 2006. Allelic replacement in Staphylococcus aureus with inducible counter-selection. Plasmid, 55(1): 58-63.

Barker, C., and Park, S. F. 2001. Sensitization of Listeria monocytogenes to low pH, organic acids, and osmotic stress by ethanol. Appl. Environ. Microbiol. 67 (4): 15941600.

Bore, E., Langsrud, S., Langsrud, O., Rode, T. M., and Holck, A. 2007. Acid-shock responses in Staphylococcus aureus investigated by global gene expression analysis. Microbiol. 153(7): 2289-2303. 
Bronner, S., Monteil, H., and Prévost, G. 2004 Regulation of virulence determinants in Staphylococcus aureus: complexity and applications. FEMS Microbiol. Rev. 28: 183200.

Campbell, J., Singh, A. K., Swoboda, J. G., Gilmore, M. S., Wilkinson, B. J., and Walker, S. 2012. An antibiotic that inhibits a late step in wall teichoic acid biosynthesis induces the cell wall stress stimulon in Staphylococcus aureus. Antimicrob. Agents Chemother. 56(4): 1810-1820. doi: 10.1128/AAC.05938-11.

Chang, W., Small, D. A., Toghrol, F., and Bentley, W. E. 2006. Global transcriptome analysis of Staphylococcus aureus response to hydrogen peroxide. J. Bacteriol. 188(4):1648-1659.

Chatterjee, I., Somerville, G. A., Heilmann, C., Sahl, H. G., Maurer, H. H., and Herrmann, M. 2006. Very low ethanol concentrations affect the viability and growth recovery in post-stationary-phase Staphylococcus aureus populations. Appl. Environ. Microbiol. 72(4): 2627-2636.

Cheung, A. L., Bayer, A. S., Zhang, G., Gresham, H., and Xiong, Y. Q. 2004. Regulation of virulence determinants in vitro and in vivo in Staphylococcus aureus. FEMS Immunol. Med. Microbiol. 40:1-9. 


\section{0_File000028_238686856.doc}

Chiou, R. Y., Phillips, R. D., Zhao, P., Doyle, M. P., and Beuchat, L. R. 2004. Ethanolmediated variations in cellular fatty acid composition and protein profiles of two genotypically different strains of Escherichia coli O157:H7. Appl. Environ. Microbiol. 70(4): 2204-2210.

Cohen, N. R., Lobritz, M .A., and Collins, J. J. 2013. Microbial persistence and the road to drug resistance. Cell Host Microbe 13(6): 632-642.

Dalebroux Z.D., Svensson, S. L., Gaynor, E. C., and Swanson, M.S. 2010. ppGpp conjures bacterial virulence. Microbiol. Mol. Biol. Rev. 74:171-199.

Davis, A. O., O'Leary, J. O., Muthaiyan, A., Langevin, M. J., Delgado, A., Abalos, A. T., Fajardo, A. R., Marek, J., Wilkinson, B. J., and Gustafson, J. E. 2005. Characterization of Staphylococcus aureus mutants expressing reduced susceptibility to common housecleaners. J. Appl. Microbiol. 98(2): 364-372.

Delgado, A., Riordan, J. T., Lamichhane-Khadka, R., Winnett, D. C., Jimenez, J., Robinson, K., O'Brien, F. G., Cantore, S. A. and Gustafson, J. E. 2007. Heterovancomycin-intermediate methicillin-resistant Staphylococcus aureus isolate from a medical center in Las Cruces, New Mexico. J. Clin. Microbiol. 45(4):1325-1329.

Dombek, K. M., and Ingram, L. O. 1984. Effects of ethanol on the Escherichia coli plasma membrane. J. Bacteriol. 157(1): 233-239. 


\section{0_File000028_238686856.doc}

Donegan, N. P., Marvin, J. S., and Cheung, A. L. 2014. Role of adaptor TrfA and ClpPC in controlling levels of SsrA-tagged proteins and antitoxins in Staphylococcus aureus. J. Bacteriol. 196(23): 4140-4151.

Donegan, N.P., Thompson, E.T., Fu, Z., and Cheung, A.L. 2010. Proteolytic regulation of toxin-antitoxin systems by ClpPC in Staphylococcus aureus. J. Bacteriol. 192(5): 1416-1422. doi: 10.1128/JB.02222-14.

Edgar, R., Domrachev, M. and Lash, A. E. 2002. Gene Expression Omnibus: NCBI gene expression and hybridization array data repository. Nucleic Acids Res. 30(1):207210.

Elsholz, A. K., Hempel, K., Pöther, D. C., Becher, D., Hecker, M., and Gerth, U. 2011. CtsR inactivation during thiol-specific stress in low GC, Gram+ bacteria. Mol. Microbiol. 79(3):772-785. doi:10.1111/j.1365-2958.2010.07489.x.

Flannagan, S. E., and Clewell D. B. 2002. Identification and characterization of genes encoding sex pheromone cAM373 activity in Enterococcus faecalis and Staphylococcus aureus. Mol. Microbiol. 44:803-817.

Fleury, B., Kelley, W. L., Lew, D., Götz, F., Proctor, R.A., and Vaudaux, P. 2009. Transcriptomic and metabolic responses of Staphylococcus aureus exposed to supraphysiological temperatures. BMC Microbiol. 9:76. doi: 10.1186/1471-2180-9-76. 


\section{0_File000028_238686856.doc}

Fried, V. A., and Novick, A. 1973. Organic solvents as probes for the structure and function of the bacterial membrane: effects of ethanol on the wild type and an ethanolresistant mutant of Escherichia coli K-12. J. Bacteriol. 114(1): 239-248.

Gaca, A. O., Colomer-Winter, C., and Lemos, J. A. 2015. Many means to a common end: the intricacies of (p)ppGpp metabolism and its control of bacterial homeostasis. J. Bacteriol. 197(7):1146-1156.

Gaupp, R., Ledala, N., and Somerville, G. A. 2012. Staphylococcal response to oxidative stress. Front. Cell. Infect. Microbiol. 16(2): 1-19.

Geiger, T., Kästle, B., Gratani, F.L., Goerke, C., and Wolz, C. 2014. Two small (p)ppGpp synthases in Staphylococcus aureus mediate tolerance against cell envelope stress conditions. J. Bacteriol. 196(4): 894-902.

Gordin, F. M., Schultz, M. E., Huber, R. A., and Gill, J. A. 2005. Reduction in nosocomial transmission of drug-resistant bacteria after introduction of an alcoholbased hand rub. Infect. Control Hosp. Epidemiol. 26(7): 650-653.

Graham, J. W., Lei, M. G., and Lee, C. Y. 2013. Trapping and identification of cellular substrates of the Staphylococcus aureus CIpC chaperone. J. Bacteriol. 195(19): 45064516. doi: 10.1128/JB.00758-13. 
Huang, S. S., Datta, R., and Platt, R. 2006. Risk of acquiring antibiotic-resistant bacteria from prior room occupants. Arch. Intern. Med. 166(18): 1945-1951.

Ibarra, J. A., Pérez-Rueda, E., Carroll, R. K., and Shaw, L. N. 2013. Global analysis of transcriptional regulators in Staphylococcus aureus. BMC Genomics, 14:126. doi: 10.1186/1471-2164-14-126.

Korem, M., Gov, Y., and Rosenberg, M. 2010. Global gene expression in Staphylococcus aureus following exposure to alcohol. Microb. Pathog. 48(2):74-84.

Kriel, A., Bittner, A. N., Kim, S .H., Liu, K., Tehranchi, A. K., Zou, W. Y., Rendon, S., Chen, R., Tu, B. P., and Wang, J. D. 2012. Direct regulation of GTP homeostasis by (p)ppGpp: a critical component of viability and stress resistance. Mol. Cell, 48:231-241. doi:10.1016/j.molcel.2012.08.009.

Larson, A. S., and Hergenrother, P. J. 2014. Light activation of Staphylococcus aureus toxin YoeBSa1 reveals guanosine-specific endoribonuclease activity. Biochemistry, 53(1):188-201.

Lee, C. Y., Buranen, S. L., and Ye, Z. H. 1991. Construction of single-copy integration vectors for Staphylococcus aureus. Gene, 103(1): 101-105. 
Lee, S. G., Lee, K. W., Park, T. H., Park, J. Y., Han, N. S., and Kim, J. H. 2012.

Proteomic analysis of proteins increased or reduced by ethanol of Lactobacillus plantarum ST4 isolated from Makgeolli, traditional Korean rice wine. J. Microbiol. Biotechnol. 22(4): 516-525.

Lilly, H. A., Lowbury, E. J., Wilkins, M. D., and Zaggy, A. 1979. Delayed antimicrobial effects of skin disinfection by alcohol. J. Hyg. (Lond). 82(3): 497-500.

Liu, S., Skory, C., Qureshi, N., and Hughes, S. 2016. The yajC gene from Lactobacillus buchneri and Escherichia coli and its role in ethanol tolerance. J. Ind. Microbiol. Biotechnol. 43(4): 441-450.

Matyi, S. A., Ramaraj, T., Sundararajan A., Lindquist, I. E., Devitt, N. P., Schilkey, F. D., Lamichhane-Khadka, R., Hoyt, P. R., Mudge J., and Gustafson, J. E. 2014. Draft genomes of heterogeneous vancomycin-intermediate Staphylococcus aureus strain MM66 and MM66 derivatives with altered vancomycin resistance levels. Gen. Announc. 2:e00688-14; doi:10.1128/genomeA.00688-14.

McDonnell, G., and Russell, A. D. 1999. Antiseptics and disinfectants: activity, action, and resistance. Clin Microbiol Rev. 12(1): 147-179.

McLaws, M. L. 2015. The relationship between hand hygiene and health careassociated infection: it's complicated. Infect. Drug Resist. 8: 7-18. 


\section{0_File000028_238686856.doc}

Meier, S., Goerke, C., Wolz, C., Seidl, K., Homerova, D., Schulthess, B., Kormanec, J., Berger-Bächi, B. and Bischoff, M. 2007. $\sigma^{\mathrm{B}}$ and the $\sigma^{\mathrm{B}}$-dependent arIRS and yabJspoVG loci affect capsule formation in Staphylococcus aureus. Infect. Immun. 75:45624571.

Michel, A., Agerer, F., Hauck, C.R., Herrmann, M., Ullrich, J., Hacker, J., and Ohlsen, K. 2006. Global regulatory impact of ClpP protease of Staphylococcus aureus on regulons involved in virulence, oxidative stress response, autolysis, and DNA repair. J. Bacteriol. 188(16): 5783-5796.

Morell, E. A., and Balkin, D. M. 2010. Methicillin-resistant Staphylococcus aureus: a pervasive pathogen highlights the need for new antimicrobial development. Yale J. Biol. Med. 83(4): 223-233.

Morikawa, K., Takemura, A.J., Inose, Y., Tsai, M., Nguyen Thi, L. T., Ohta, T., and Msadek, T. 2012. Expression of a cryptic secondary sigma factor gene unveils natural competence for DNA transformation in Staphylococcus aureus. PLoS Pathog. 8(11): e1003003. doi: 10.1371/journal.ppat.1003003.

Muthaiyan, A., Silverman, J. A., Jayaswal, R. K. and Wilkinson, B. J. 2008.

Transcriptional profiling reveals that daptomycin induces the Staphylococcus aureus cell wall stress stimulon and genes responsive to membrane depolarization. Antimicrob. Agents Chemother. 52(3): 980-990. 


\section{0_File000028_238686856.doc}

Nagarajan, V. and Elasri, M. O. 2007. SAMMD: Staphylococcus aureus microarray meta-database. BMC Genomics, 8: 351. doi: 10.1186/1471-2164-8-351.

O’Brien, F. G., Lim, T. T., Winnett, D. C., Coombs, G. W., Pearson, J. C., Delgado, A., Langevin, M. J., Cantore, S. A., Gonzalez, L., and Gustafson, J. E. 2005. Survey of methicillin-resistant Staphylococcus aureus strains from two hospitals in El Paso, Texas. J. Clin. Microbiol. 43:2979-2972.

Overton, I. M., Graham, S., Gould, K. A., Hinds, J., Botting, C. H., Shirran, S., Barton, G. J., and Coote, P. J. 2011. Global network analysis of drug tolerance, mode of action and virulence in methicillin-resistant S. aureus. BMC Syst. Biol. 5: 68. doi: 10.1186/1752-0509-5-68.

Prosser, G. A., Larrouy-Maumus, G., and de Carvalho, L. P. 2014. Metabolomic strategies for the identification of new enzyme functions and metabolic pathways. EMBO Rep. 15(6): 657-669. doi: 10.15252/embr.201338283.

Qoronfleh, M. W., Gustafson, J. E., and Wilkinson, B. J. 1998. Conditions that induce Staphylococcus aureus heat shock proteins also inhibit autolysis. FEMS Microbiol. Lett. 166(1): 103-107.

Reiss, S., Pané-Farré, J., Fuchs, S., François, P., Liebeke, M., Schrenzel, J., Lindequist, U., Lalk, M., Wolz, C., Hecker, M., and Engelmann, S. 2012. Global analysis 
of the Staphylococcus aureus response to mupirocin. Antimicrob. Agents Chemother. 56(2): 787-804.

Riordan, J. T., Muthaiyan, A., Van Voorhies, W., Price, C. T., Graham, J. E., Wilkinson, B. J. and Gustafson, J. E. 2007. Response of Staphylococcus aureus to salicylate challenge. J. Bacteriol. 189(1): 220-227.

Schuster, C. F., Mechler, L., Nolle, N., Krismer, B., Zelder, M. E., Götz, F., and Bertram, R. 2015. The MazEF Toxin-Antitoxin System Alters the $\beta$-Lactam Susceptibility of Staphylococcus aureus. PLoS One, 10(5): e0126118. doi:

10.1371/journal.pone.0126118.

Senn, M. M., Bischoff, M., von Eiff, C., and Berger-Bächi, B. 2005. $\sigma^{B}$ activity in a Staphylococcus aureus hemB mutant. J. Bacteriol. 187(21): 7397-7406.

Shrihari, R. Y., and Singh, N. P. 2012. Multiplex reverse transcription polymerase chain reaction to study the expression of virulence and stress response genes in Staphylococcus aureus. J. Food Sci. 77(2): M95-101. doi: 10.1111/j.17503841.2011.02542.x.

Siegel, J. D., Rhinehart, E., Jackson, M., Chiarello, L., and the Healthcare Infection Control Practices Advisory Committee, 2007 Guideline for Isolation Precautions: 
Preventing Transmission of Infectious Agents in Healthcare Settings.

http://www.cdc.gov/ncidod/dhqp/pdf/isolation2007.pdf. Accessed Nov. 3, 2015.

Song, Y., Lunde, C. S., Benton, B. M., and Wilkinson, B. J. 2012. Further insights into the mode of action of the lipoglycopeptide telavancin through global gene expression studies. Antimicrob. Agents Chemother. 56(6): 3157-3164.

Tang, Y. W., and Stratton, C. W. 2010. Staphylococcus aureus: An old pathogen with new weapons. Clin Lab. Med. 30(1): 179-208. Review.

Todd, E. C., Michaels, B. S., Holah, J., Smith, D., Greig, J. D., and Bartleson, C. A. 2010. Outbreaks where food workers have been implicated in the spread of foodborne disease. Part 10. Alcohol-based antiseptics for hand disinfection and a comparison of their effectiveness with soaps. J. Food Prot. 73(11): 2128-2140. Review.

Vercruysse, M., Fauvart, M., Jans, A., Beullens, S., Braeken, K., Cloots, L., Engelen, K., Marchal, K., and Michiels, J. 2011. Stress response regulators identified through genome-wide transcriptome analysis of the ( $\mathrm{p}) \mathrm{ppGpp}$-dependent response in Rhizobium etli. Genome Biol. 12(2): R17. doi: 10.1186/gb-2011-12-2-r17.

Wood, T. K., Knabel S. J., and Kwan B. W. 2013. Bacterial persister cell formation and dormancy. Appl. Environ. Microbiol. 79(23): 7116-7121. 


\section{0_File000028_238686856.doc}

World Health Organization. 2009. WHO Guidelines on Hand Hygiene in Health Care.

First Global Patient Safety Challenge: Clean Care Is Safer Care.

http://whqlibdoc.who.int/publications/2009/9789241597906_eng.pdf. Accessed Nov. 3, 2015.

Wozniak, D. J., Tiwari, K. B., Soufan, R., and Jayaswal, R. K. 2012. The mcsB gene of the $c l p C$ operon is required for stress tolerance and virulence in Staphylococcus aureus. Microbiology, 158(Pt 10): 2568-2576.

Zhang, Y. 2014. Persisters, persistent infections and the Yin-Yang model. Emerg. Microbes Infect. 3(1): e3. doi:10.1038/emi.2014.3.

Zhang, Y., Yew, W. W., and Barer, M. R. 2012. Targeting persisters for tuberculosis control. Antimicrob. Agents Chemother. 56(5): 2223-2230. Review. doi: 10.1128/AAC.06288-11. 


\section{Tables}

Table 1. Primers utilized in this study.

Table 2. qRT-PCR results for four genes differentially regulated in S. aureus following ethanol exposure.

Table 3. High expression-change genes, differentially regulated by at least 15 -fold in LP9 and/or MM66 by ethanol exposure.

Table 4. The 11 up-regulated genes from the four high-overlap SATMD transcriptomes also among the ethanol exposure high-expression change genes.

\section{Figure Captions}

Figure 1. MICs (A) and MBCs (B) of 106 clinical MRSA to ethanol (\% v/v).

Figure 2. Venn diagrams of LP9 and MM66 for (A) all genes differentially regulated, (B) genes up-regulated, and (C) genes down-regulated by ethanol exposure.

Figure 3. Numbers of up- and down-regulated LP9 (open bars) and MM66 (solid bars) genes by gene functional category in response to ethanol exposure.

Figure 4. Numbers of up- and down-regulated LP9 (open bars) and MM66 (solid bars) genes by relevant gene functional sub-category in response to ethanol exposure.

Figure 5. Ethanol (9\% v/v) challenged growth assay. 


\section{0_File000028_238686856.doc}

Figure 6. Numbers of genes by functional category for the 85 genes up-regulated in at least three transcriptional profiles among those for ethanol exposure and the four highoverlap SATMD environmental stress conditions.

\section{Supplementary Material}

Table S1. Ethanol MICs and MBCs.

Table S2. Ethanol exposure transcriptomic data for LP9 and MM66 as two-fold or greater expression changes by gene functional category; ND = Not Differentially regulated (< two-fold expression change).

Table S3. Numbers of differential gene expressions and genes involved by ethanol exposure by direction of expression change, strain, and gene functional category and sub-category.

Table S4. Differential regulation of 49 LP9 and MM66 ribosomal protein-encoding genes in response to ethanol exposure.

Table S5. Eighty-five genes up-regulated $(\checkmark)$ in at least three transcriptional profiles among those for ethanol exposure and the four high-overlap SATMD environmental stress conditions.

Figure S1. Growth response of MRSA LP9 (circles) and MM66 (squares) following 10\% ethanol addition (open markers) vs. growth without ethanol (solid markers). 
Table 1.

\begin{tabular}{|c|c|c|}
\hline RT-qPCR primers & Gene & Sequence $5^{\prime} \rightarrow 3^{\prime}$ \\
\hline $\begin{array}{l}\text { SA0481-F } \\
\text { SA0481-R } \\
\text { SA0835-F } \\
\text { SA0835-R } \\
\text { SA2307-F } \\
\text { SA2307-R }\end{array}$ & $\begin{array}{l}m c s A \\
c l p B\end{array}$ & $\begin{array}{l}\text { TGCACATGTTGGTAAATTTGG } \\
\text { TTGTCCACCTTGAACTCTGC } \\
\text { CAAGCAGCACTTCAATCTCG } \\
\text { TGTTTGTGCATCTTCCAACG } \\
\text { GTTGCCATTTGAAGAAGTCG } \\
\text { ATTTCAATGGGGCCTAATCC }\end{array}$ \\
\hline \multicolumn{3}{|c|}{ relP inactivation and complementation primers } \\
\hline $\begin{array}{l}\text { attB1-relP-up:F } \\
\text { relP-up:R:Sacll } \\
\text { relP-down:F:Sacll } \\
\text { attB1-relP-down:R }\end{array}$ & & $\begin{array}{l}\text { GGGGACAAGTTTGTACAAAAAAGCAGGCTAAGATAGACTTACAATAAATGAACA } \\
\text { AGGATTCCGCGGTCGATCTACATACATTTTTATACTAA } \\
\text { AGGATTCCGCGGGAGTAGATGTTTAGTAGGTGT } \\
\text { GGGGACCACTTTGTACAAGAAAGCTGGGTCGAGCACTAAAATAGTGAC }\end{array}$ \\
\hline $\begin{array}{l}\text { relP:F:Kpnl } \\
\text { relP:R:Xbal }\end{array}$ & & $\begin{array}{l}\text { GGGGTACCGATTGGTATCGAGCGTTATCG } \\
\text { TGCTCTAGACACACCTACTAAACATCTACTC }\end{array}$ \\
\hline
\end{tabular}

Table 2.

\begin{tabular}{|c|c|c|c|c|c|c|}
\hline \multirow[t]{2}{*}{ Locus ID } & \multirow[t]{2}{*}{ Gene } & \multirow[t]{2}{*}{ Gene product } & \multicolumn{4}{|c|}{ Fold-change in gene expression } \\
\hline & & & LP9 & (qRT-PCR) & MM66 & (qRT-PCR) \\
\hline SA0481 & $m c s A$ & protein-arginine kinase activator protein McsA & 19.7 & 4.9 & 15.8 & 33.5 \\
\hline SA0835 & $c / p B$ & ClpB chaperone homolog & 52.2 & 2.6 & 67.1 & 31.3 \\
\hline SA2307 & & similar to chlorophenol degradation dioxygenase PcpA & 28.4 & 2.4 & 8.1 & 3.2 \\
\hline
\end{tabular}


Table 3.

\begin{tabular}{|c|c|c|c|c|c|}
\hline Gene functional category & Locus ID & Gene & Gene product & LP9 & MM66 \\
\hline Cell envelope metabolism and resistances & SA2308 & NA & transcriptional regulator, MarR family & 21.8 & ND \\
\hline Cell envelope metabolism and resistances & SA2343 & cwrA & cell wall damage-inducible protein CwrA & ND & 17.7 \\
\hline Central intermediary metabolism & SA0562 & adh1 & alcohol dehydrogenase & -8.2 & -18.4 \\
\hline DNA replication, recombination and repair & SA1562 & NA & putative cell division protein FtsK & 16.9 & 3.9 \\
\hline Hypothetical proteins & SA0957 & NA & hypothetical protein & 11.7 & 34.1 \\
\hline Hypothetical proteins & SA1000 & NA & hypothetical protein & 12.7 & 16.7 \\
\hline Hypothetical proteins & SACOL0768 & NA & hypothetical protein & 16.2 & 17.5 \\
\hline Unknown function & SACOL1165 & NA & hypothetical membrane protein & 14.5 & 19.9 \\
\hline Hypothetical proteins & SAS037 & NA & hypothetical protein & 13.1 & 30.7 \\
\hline Nitrogen metabolism & SA2185 & narG & respiratory nitrate reductase, alpha subunit & -3.2 & -19.1 \\
\hline Nitrogen metabolism & SA2188 & nas $D$ & nitrite reductase, large subunit & -3.8 & -15.5 \\
\hline Cofactors and secondary metabolites & SA2189 & NA & similar to NirR protein & -3.3 & -18.5 \\
\hline Nucleotide metabolism & SA1018 & NA & noncanonical pyrimidine nucleotidase, YjjG family & 12.2 & 24.9 \\
\hline Nucleotide metabolism & SA2438 & NA & $\mathrm{N}$-carbamoylsarcosine amidohydrolase & 8.4 & 15.2 \\
\hline Protein fate & SA0803 & ampA & probable cytosol aminopeptidase & 13.2 & 19 \\
\hline Protein fate & SA1215 & NA & hypothetical, similar to preprotein translocase & 6.2 & 15.3 \\
\hline Protein fate & SA1216 & NA & oligoendopeptidase F, putative & 23.8 & 35 \\
\hline Protein fate & SA1343 & NA & similar to tripeptidase PepT & 12.8 & 18.8 \\
\hline Protein synthesis & SA2042 & $r p / V$ & ribosomal protein L22 & -5.8 & -19.1 \\
\hline Stress response - general & SA0480 & $\operatorname{cts} R$ & CtsR transcription repressor of class III stress genes & 26.2 & 23.1 \\
\hline Stress response - general & SA0481 & $m c s A$ & protein-arginine kinase activator protein McsA & 19.7 & 15.8 \\
\hline
\end{tabular}


Stress response - general

Stress response - general

Stress response - general

Stress response - heat shock

Stress response - heat shock

Stress response - other

Stringent response

Transcription

Transcription

Transport

Virulence factor - secreted

Virulence factor - secreted

$\begin{array}{lll}\text { SA0482 } & m c s B & \text { protein-arginine kinase McsB } \\ \text { SA0483 } & c l p C & \text { Clp protease, ATP-binding subunit ClpC, frameshift } \\ \text { SA0835 } & c l p B & \text { ClpB chaperone homolog } \\ \text { SA1410 } & \text { grpE } & \text { heat shock protein GrpE } \\ \text { SA1837 } & \text { groES } & \text { heat shock protein GroES } \\ \text { SA2307 } & \text { NA } & \text { similar to chlorophenol degradation dioxygenase PcpA } \\ \text { SA2297 } & \text { relP } & \text { GTP pyrophosphokinase } \\ \text { SA2023 } & \text { rpoA } & \text { DNA-directed RNA polymerase alpha subunit } \\ \text { SAS010 } & \text { NA } & \text { hypothetical XRE family transcriptional regulator } \\ \text { SA2227 } & \text { NA } & \text { amino acid ABC transporter homolog } \\ \text { SA0746 } & \text { NA } & \text { staphylococcal thermonuclease homolog } \\ \text { SA2207 } & \text { hlgA } & \text { gamma-hemolysin chain II precursor }\end{array}$

27.9

17

52.2

13.5

18

28.4

20.4

$-7.9$

5.6

$-10.1$

8.8

10.4
13.1

14.1

67.1

15.6

10.3

8.1

23.2

$-17$

15.9

$-15.8$

24.8

20.2 
Table 4.

\begin{tabular}{|c|c|c|c|c|c|c|c|c|}
\hline Gene functional category & Locus ID & Gene & Upregulated gene product & $\begin{array}{c}\text { Ethanol } \\
10 \% \\
15 \mathrm{~min}\end{array}$ & $\begin{array}{c}\text { Heat shock } \\
43^{\circ} \mathrm{C} \\
10 \mathrm{~min}\end{array}$ & $\begin{array}{l}\text { Enduracidin } \\
10 \times \mathrm{MIC} \\
60 \mathrm{~min}\end{array}$ & $\begin{array}{l}\text { Vancomycin } \\
10 x M I C \\
60 \mathrm{~min}\end{array}$ & $\begin{array}{c}\text { Acid shock } \\
\mathrm{pH} 4.5 \\
5 \mathrm{~min}\end{array}$ \\
\hline Protein fate & SA1215 & NA & hypothetical, similar to preprotein translocase & $\checkmark$ & & $\checkmark$ & $\checkmark$ & \\
\hline Stress response - general & SA0480 & $\operatorname{cts} R$ & CtsR class III stress gene transcription repressor & $\checkmark$ & $\checkmark$ & $\checkmark$ & & $\checkmark$ \\
\hline Stress response - general & SA0481 & $m c s A$ & Protein-arginine kinase activator protein McsA & $\checkmark$ & $\checkmark$ & $\checkmark$ & & $\checkmark$ \\
\hline Stress response - general & SA0482 & $m c s B$ & Protein-arginine kinase McsB & $\checkmark$ & $\checkmark$ & $\checkmark$ & & $\checkmark$ \\
\hline Stress response - general & SA0483 & $c / p C$ & Clp protease ATP-binding subunit $\mathrm{ClpC}$, frameshift & $\checkmark$ & $\checkmark$ & $\checkmark$ & & $\checkmark$ \\
\hline Stress response - general & SA0835 & $c / p B$ & ClpB chaperone homolog & $\checkmark$ & $\checkmark$ & $\checkmark$ & & $\checkmark$ \\
\hline Stress Response - heat Shock & SA1410 & grpE & heat shock protein GrpE & $\checkmark$ & $\checkmark$ & $\checkmark$ & & \\
\hline Stress Response - heat Shock & SA1837 & groES & heat shock protein GroES & $\checkmark$ & $\checkmark$ & $\checkmark$ & & \\
\hline Stringent response & SA2297 & relP & GTP pyrophosphokinase & $\checkmark$ & & $\checkmark$ & $\checkmark$ & \\
\hline Transcription & SAS010 & NA & hypothetical XRE family transcriptional regulator & $\checkmark$ & & $\checkmark$ & $\checkmark$ & \\
\hline Virulence factor - secreted & SA2207 & $h \lg A$ & gamma-hemolysin chain II precursor & $\checkmark$ & & $\checkmark$ & $\checkmark$ & \\
\hline
\end{tabular}



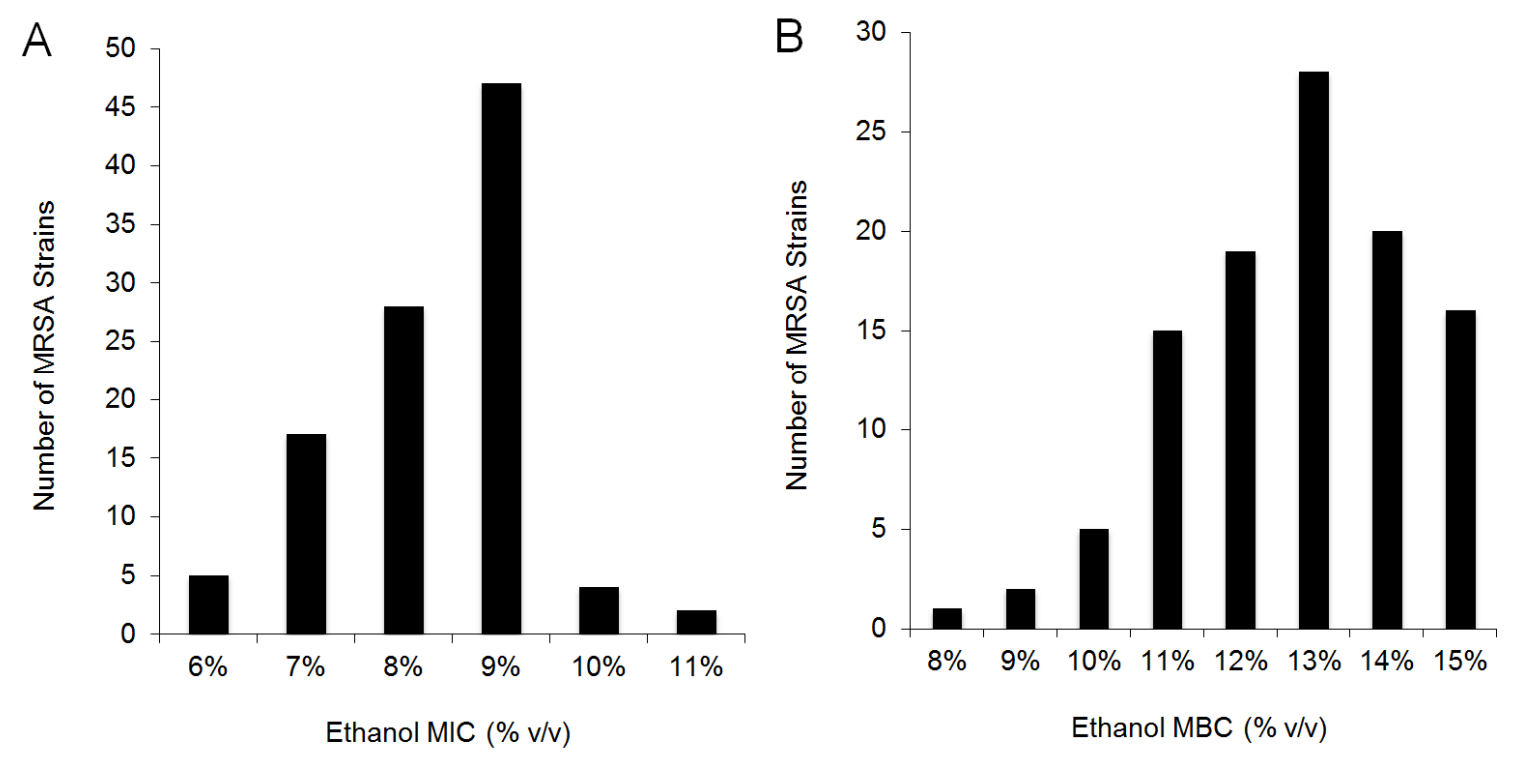

Figure 1. 

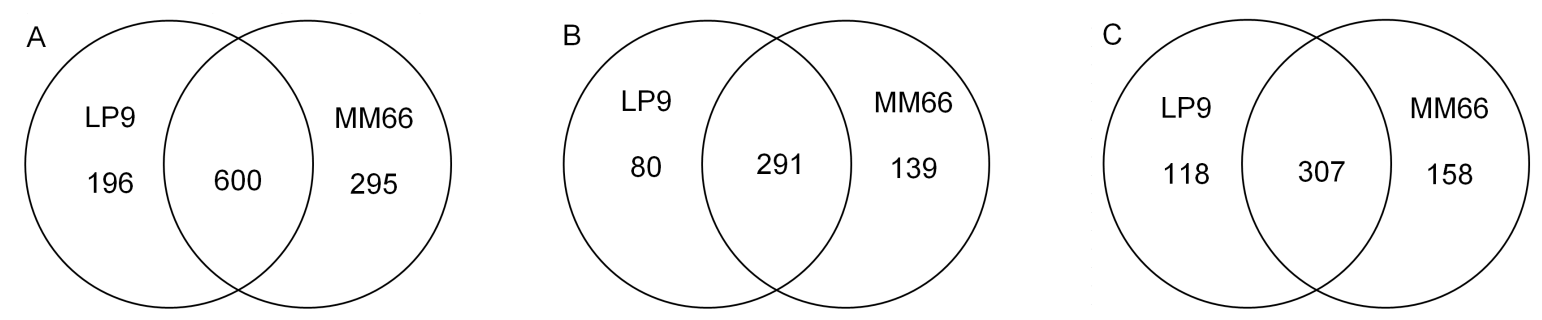

Figure 2. 


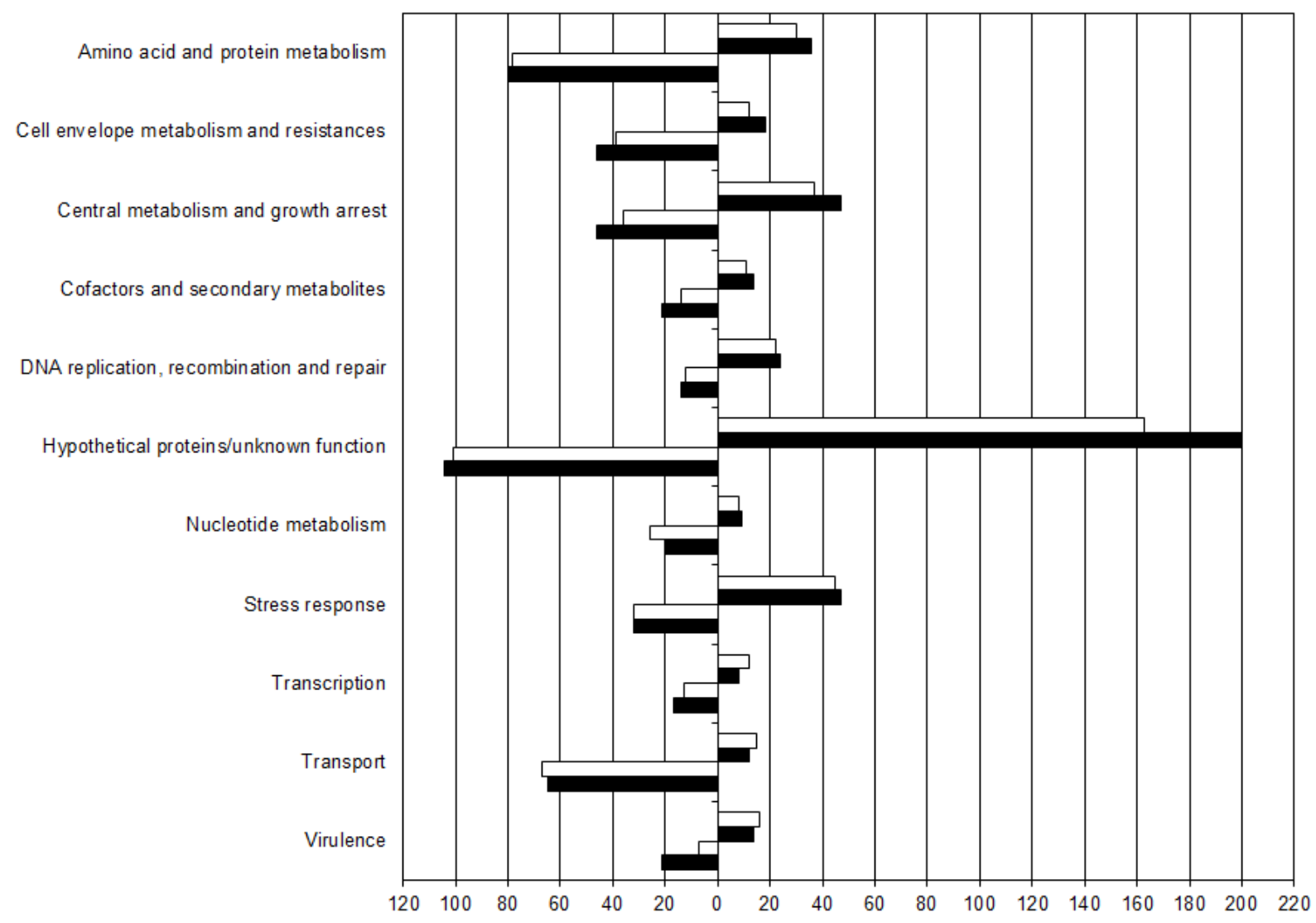

Figure 3. 


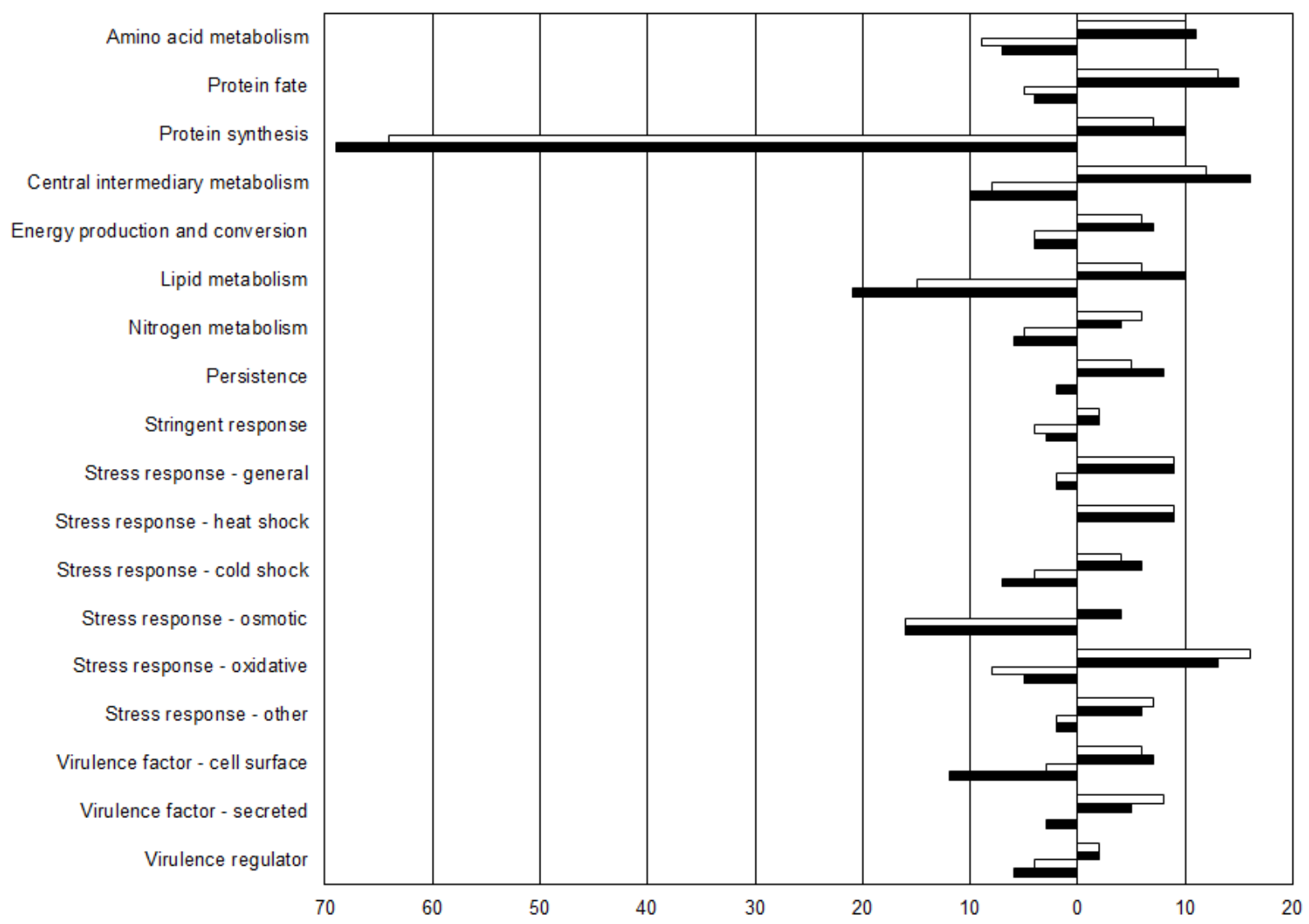

Figure 4. 


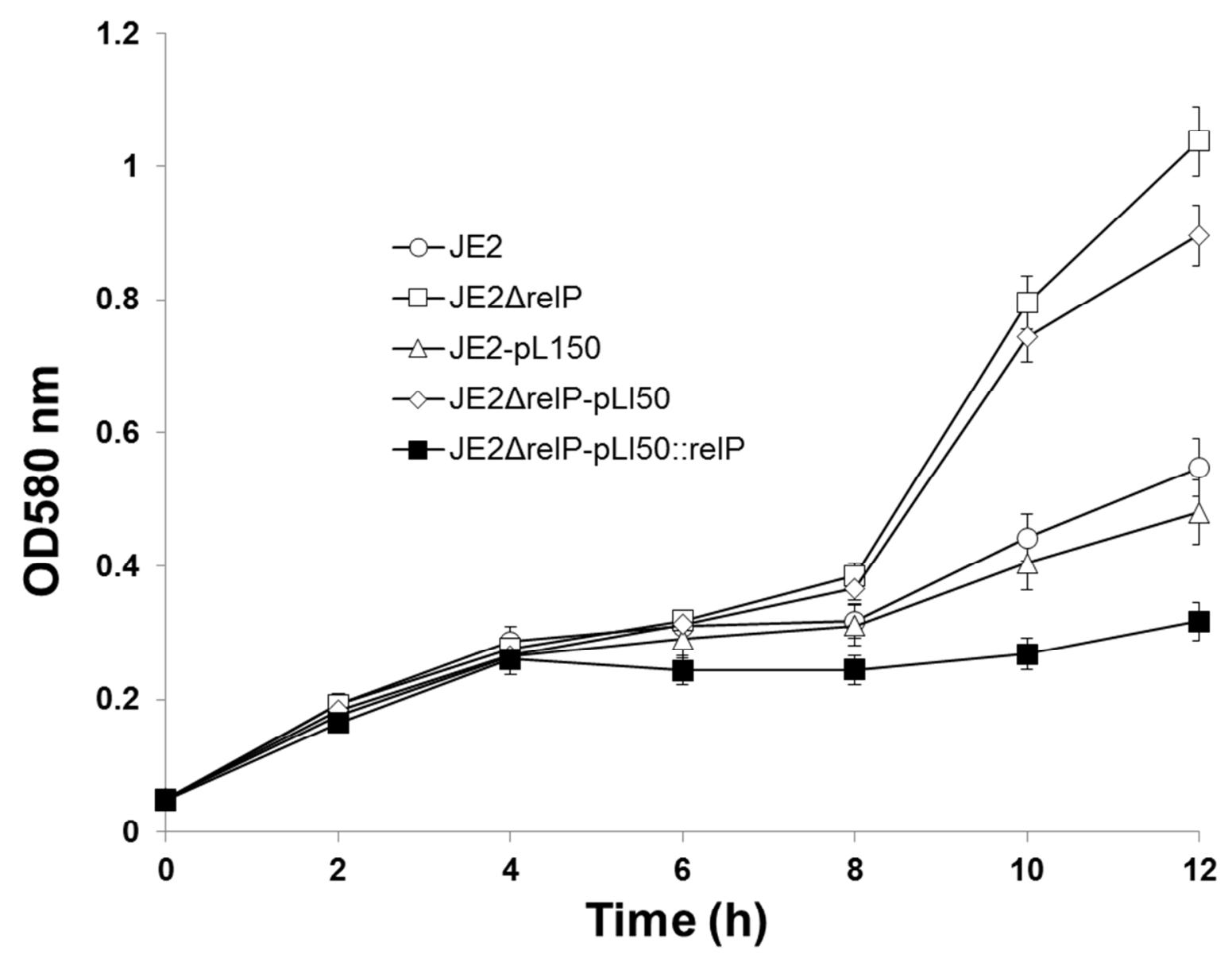

Figure 5. 


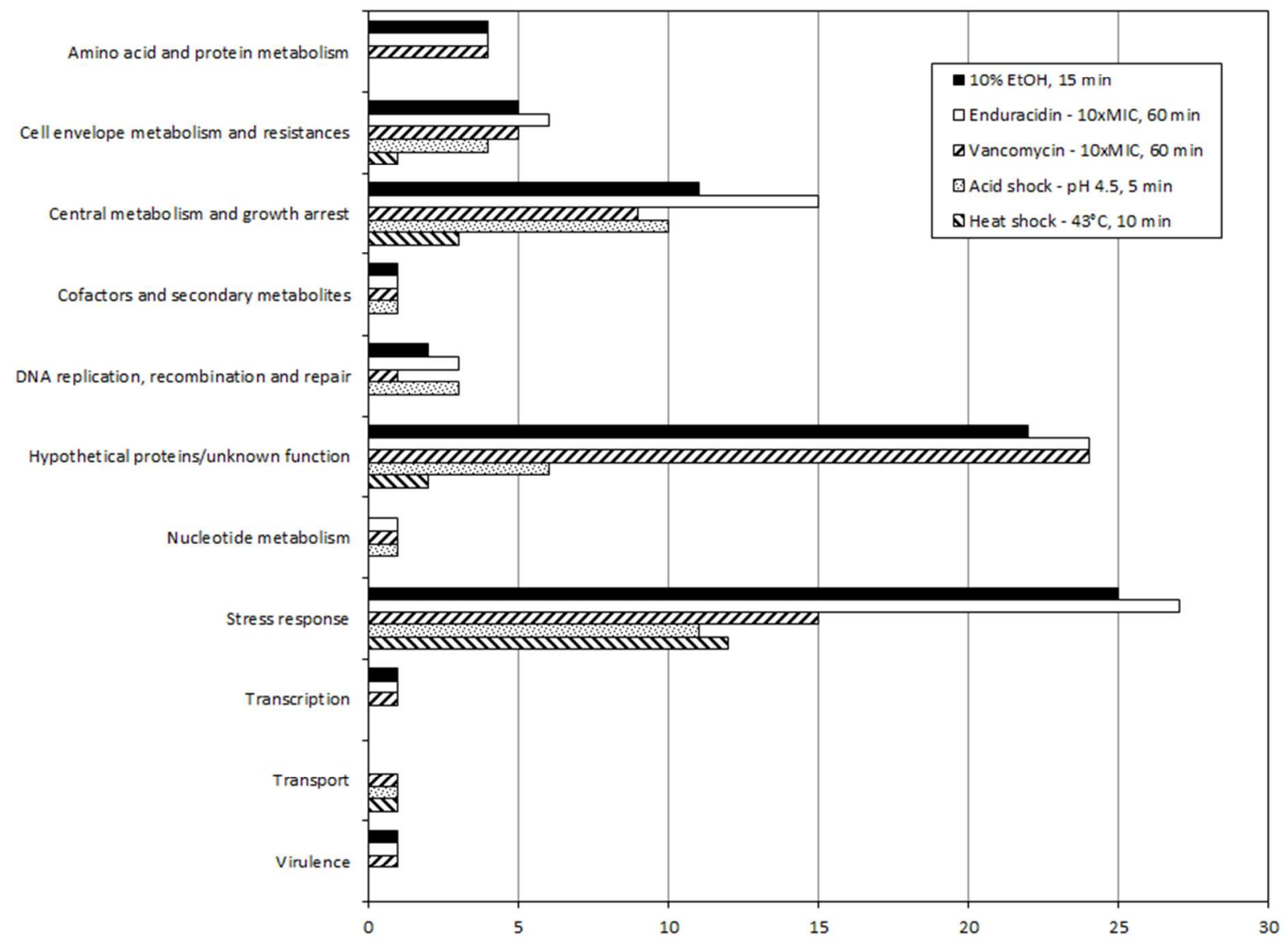

Figure 6. 